\title{
ON D'AURIZIO'S TRIGONOMETRIC INEQUALITY
}

\section{JÓZSEF SÁNDOR}

Abstract. We offer new proof of the recent sharp trigonometric inequality $\cos x / \cos (x / 2) \geqslant$ $1-4 x^{2} / \pi^{2}$ for $x \in(0, \pi / 2)$, discovered by Jacopo D'aurizio [1]. The converse inequality, as well as sharp analogous inequalities are pointed out, too.

Mathematics subject classification (2010): 26D05, 26 D99.

Keywords and phrases: Inequalities, trigonometric functions, Cusa-Huygens inequality, monotonicity.

\section{REFERENCES}

[1] J. D'AURIZIO, Refinements of the Shafer-Fink inequality of arbitrary uniform precision, Math. Ineq. Appl. 17 (2014), no. 4, 1487-1498.

[2] J. SÁNDOR, Two sharp inequalities for trigonometric and hyperbolic functions, Math. Ineq. Appl. 15 (2012), no. 2, 409-413.

[3] J. SÁNDOR, On new refinements of Kober's and Jordan's trigonometric inequalities, Notes Number Theory Discrete Math. 19 (2013), no. 1, 73-83. 